\title{
Morbidity pattern amongst under-five children and associated factors in a rural area of Varanasi district in Uttar Pradesh, India
}

\author{
Malik Faizan Ahmad ${ }^{1}$, Divya Khanna ${ }^{2, *}$ \\ ${ }^{1,2}$ Assistant Professor, Dept. of Community Medicine, Heritage Institute of Medical Sciences, Varanasi, Uttar Pradesh, India
}

*Corresponding Author:

Email: dkhannakgmc@gmail.com

\begin{abstract}
Introduction: Acute respiratory tract infection (ARI), diarrhoea, measles, malaria are regarded as the most important killers of under-five children. Anemia and worm infestation adds to the misery of the growing children. Neonatal deaths accounted for $46 \%$ of under-five deaths in 2016.

Materials and Methods: A community-based cross-sectional observational study was done in the rural area of Todarpur Village of Varanasi district of Uttar Pradesh India, which is the field practice area of Rural Health Training Centre under the Department of Community Medicine, Heritage Institute of Medical Sciences. The study period was January-April 2018. The data was collected through pretested schedule using operational definition for morbidities. Data was analysed using SPSS version 16.0 and Fischer's exact test of significance was used to find statistically significant difference in distribution of risk factors amongst children who developed morbidity and who did not.

Results: The most common morbidity reported by the care givers of the children was ARI (33.2\%), followed by fever (26.5\%), anemia (15.2\%), diarrhoea (11.4\%), worm infestation $(9.5 \%)$.

Conclusion: Under-five is the most vulnerable group for mortality and this section of the population is the foundation of a healthy developed nation. Having healthy growth and development is not only a health related demand but also an issue of human rights. Thus appropriate cost-effective strategies and intervention are needed to reduce the burden of morbidity in this critical age group.
\end{abstract}

Keywords: Morbidity pattern, Under-five, Risk factors, Rural India, ARI, Diarrhoea.

\section{Introduction}

India contributes for 2.1 million of the 9.7 million annual under-five child deaths globally, thus accounting for 21 per cent of the global burden of child deaths. ${ }^{1}$ Infectious diseases like diarrhoea, acute respiratory infections, malaria are reported as world's leading cause of morbidity and mortality in children especially in developing countries. In India, common morbidities among children are fever, acute respiratory infections (ARI), diarrhoea and malnutrition. ${ }^{2}$ During this period about $40 \%$ of physical growth and $80 \%$ of mental development occurs. ${ }^{3}$ Any adverse influences during this period may result in severe limitations in their development. This age group is most affected by various common and easily treatable illnesses. A number of child survival strategies implemented by GOI has resulted in impressive improvement in morbidity and mortality indicators but the results have not been consistent. ${ }^{4}$ The World Health Organization estimates that seeking prompt and appropriate care could reduce child deaths due to acute respiratory infections by 20 percent. ${ }^{5}$ In this context the present study was conducted to determine the morbidity pattern and its risk factors amongst under-five children in a rural area of Varanasi district in Uttar Pradesh, India.

\section{Materials and Methods}

A community based cross-sectional observational study was done in the rural area of Todarpur Village of Varanasi district of Uttar Pradesh India, which is the field practice area of Rural Health Training Centre under the Department of Community Medicine, Heritage Institute of Medical Sciences. The Study period was January-April, 2018. A multistage sampling technique was followed. The list of sub-centres was prepared and one sub-centre was randomly selected. Then a list of village of the sub-centre Todarpur was prepared and one village, was randomly selected. The area was chosen because of better support. A total of 219 under-five children were incorporated in the study. From the Census 2011 data $^{6}$, the population of underfive children in India is $10.7 \%$, hence in a village of population 1850 , number of under-five children will be 198. Therefore the sample size would be 198 but a total of 200 under-five children were considered in the study. During the final survey and enumeration of the population, 8 babies were born and 11 immigrated which are also included in the study and total 219 children of under five years of age are selected finally.

All under-five children were considered for the study after having informed consent from parents or caregivers. Study was conducted by house-to-house visit in study area. Information of the individual and family was collected by pre-designed, pre-tested and semi-structured proforma. A pre-tested structured questionnaire was used to collect the data regarding age, sex, mother's education, socioeconomic status, status of immunization, breast-feeding, birth-weight, birth order and inter-pregnancy interval. To identify retrospective morbidity of children, the mothers were asked about the development of related signs and symptom in child in the preceding two weeks; if the 
child had been sick in the last 2 weeks. Mothers were asked to recall about the probable nature of the illness based on operational case definitions taken from ICD$10 .^{7}$ All the children covered for study were clinically examined clinically for the presence of signs of morbidity at the time of interview.

Data was entered in the MS Excel 2007 and analysis was done in SPSS 16.0. Results were expressed in frequencies and proportions. Fischer's exact test of significance was used to find statistically significant difference in distribution of risk factors amongst children who developed morbidity and who did not. $\mathrm{P}$ value of $<0.05$ was considered as statistically significant.

Ethical Consideration: The study was given ethical clearance from the Institution Ethical Review Committee. Parents /guardians of the children were informed about the study and invited to participate in the study. Informed verbal consent was obtained from the parents/guardians. Children identified with unhealthy conditions/diseases were examined and treated by the investigator under the guidance of Expert. Participants who required further management and follow up were referred to the higher centre.

\section{Results}

We found that out of 219 children more than half were females $(55 \%)$. Nearly one fourth of the children were infants (0-11 months) and one fourth were 4-5 year old. Majority of the Infants were females (78.9\%). Out of 219 children $211(96.3 \%)$ were found to have some form of morbidity or sickness from the preceding two weeks till the point of interview. The most common morbidity reported by the care givers of the children was acute respiratory infection. (ARI) (33.2\%), followed by fever $(26.5 \%)$, anemia (15.2\%), diarrhoea $(11.4 \%)$, worm infestation $(9.5 \%)$. Only 5 cases were seen of skin infection ( 2 scabies, 3 ring worms) and two cases each gave history of measles and malaria in the preceding two weeks. (Table 1)

It was seen that more than half $(58 \%)$ of the children were immunized till the date. Less than half of the children had received exclusive breast feeding for 6 months (40.6\%.). Nearly two-third (66.7\%) of the children were delivered at an institution but two-fifth $(40.2 \%)$ children were born with low birth weight $(<2.5 \mathrm{~kg})$. Birth order of more than half $(56.2 \%)$ of the children was $>4$. Mothers of more than two-fifth $(44.3 \%)$ were illiterate and could not read or write. Again more than two-fifth $(45.2 \%)$ of the children belonged to poor socioeconomic status (SE Class IVV). (Table 2)

The distribution of presence or absence of the mentioned morbidities was compared amongst the study population with specific factors. It was seen that statistically significant difference in distribution of history of exclusive breast feeding for 6 months, higher birth order $(>4)$ and inter pregnancy interval for the index child ( $\geq 3$ years) were found amongst those who developed morbidity and those who did not. However, immunization status of the child, place of delivery, birth weight, mothers literacy status, socio-economic class and gender of the child had no significant difference in distribution. (Table 2)

\section{Discussion}

We found that the most common morbidity reported by the care givers of the children was ARI. $(33.2 \%)$, followed by fever $(26.5 \%)$, anemia $(15.2 \%)$, diarrhoea $(11.4 \%)$, worm infestation $(9.5 \%)$. Only 5 cases were seen of skin infection ( 2 scabies, 3 ring worms) and two cases each gave history of measles and malaria in the preceding two weeks. Our finding is partly in line with a study from Lucknow district that reported ARI as the most common morbidity followed by diarrhoea and fever. However there was difference in observation of frequency of diarrhoea which can be partly explained due to our study period restricted to Jan-April which may had masked the seasonal variations. ${ }^{8}$ (Table 1 )

It was seen that more than half $(58 \%)$ of the children were immunized till the date. This figure is lower in comparison to the figure from NFHS-4 data of rural Uttar Pradesh which states the percentage of children age 12-23 months fully immunized (BCG, measles, and 3 doses each of polio and DPT) to be $50.4 \%$. $^{9}$ Less than half of the children had received exclusive breast feeding for 6 months (40.6\%). This figure is line with the figure from NFHS-4 data of rural Uttar Pradesh which states the percentage of children who had received exclusive breast feeding to be $43 \%$. Nearly two-third $(66.7 \%)$ of the children were delivered at an institution. This figure is similar to the figure from NFHS-4 data of rural Uttar Pradesh which states the percentage of institutional delivery as $66.8 \%{ }^{9}$ However, two-fifth $(40.2 \%)$ children were born with low birth weight $(<2.5 \mathrm{~kg})$ which was much higher in comparison to figure from India $(20 \%) .{ }^{10}$ Mothers of more than two-fifth $(44.3 \%)$ were illiterate and could not read or write. The finding was similar to the finding from NFHS-4 stating the illiteracy amongst women from rural Uttar Pradesh to be $43.8 \% .^{9}$ (Table 2)

The distribution of presence or absence of the mentioned morbidities was compared amongst the study population with specific factors. It was seen that statistically significant difference in distribution of history of exclusive breast feeding for 6 months, higher birth order $(>4)$ and inter pregnancy interval for the index child ( $\geq 3$ years) were found amongst those who developed morbidity and those who did not. However, immunization status of the child, place of delivery, birth weight, Mothers literacy status, Socio-economic class and gender of the child had no significant difference in distribution. This may be partly due to smaller sample size which may have masked the weaker associated factors. Our finding is in line with several other studies 
that have identified lack of exclusive breast feeding and neonatal and under-five mortality. ${ }^{11-13}$ (Table 2) too many and too soon pregnancies as a risk factor for

Table 1: Distribution of morbidities in the under-five children

\begin{tabular}{|l|c|c|}
\hline Morbidity & \multicolumn{2}{|c|}{ Children } \\
\cline { 2 - 3 } (reported in the last 2 weeks preceding the survey) & Number & \% \\
\hline Acute respiratory infection(ARI) & 70 & 33.2 \\
\hline Fever & 56 & 26.5 \\
\hline Anemia & 32 & 15.2 \\
\hline Diarrhoea & 24 & 11.4 \\
\hline Worm infestation & 20 & 9.5 \\
\hline Skin infection & 5 & 2.4 \\
\hline Measles & 2 & 0.9 \\
\hline Malaria & 2 & 0.9 \\
\hline Total & $\mathbf{2 1 1}$ & $\mathbf{1 0 0}$ \\
\hline
\end{tabular}

Table 2: Factors influencing the morbidity status of the under-five children $(n=219)$

\begin{tabular}{|c|c|c|c|c|c|}
\hline \multirow[t]{2}{*}{ Factors } & \multirow[t]{2}{*}{ Sub-category } & \multicolumn{2}{|c|}{ Morbidity status } & \multirow[t]{2}{*}{ Total } & \multirow{2}{*}{$\begin{array}{l}\text { Test of significance } \\
\text { (p value of Fisher's } \\
\text { Exact test) }\end{array}$} \\
\hline & & $\begin{array}{c}\text { Present } \\
\mathrm{N}=211 \\
(\%)\end{array}$ & $\begin{array}{c}\text { Absent } \\
\mathrm{N}=8 \\
(\%)\end{array}$ & & \\
\hline \multirow[t]{2}{*}{ Immunization status } & Full & $121(57.3)$ & $6(75)$ & $127(58)$ & \multirow[t]{2}{*}{0.47} \\
\hline & Partial & $90(42.7)$ & $2(25)$ & $92(42)$ & \\
\hline \multirow{2}{*}{$\begin{array}{l}\text { Exclusive Breast } \\
\text { Feeding for } 6 \text { months }\end{array}$} & Yes & $82(38.9)$ & $7(87.5)$ & $89(40.6)$ & \multirow[t]{2}{*}{$0.008^{*}$} \\
\hline & No & $129(61.1)$ & $1(12.5)$ & $130(59.4)$ & \\
\hline \multirow[t]{2}{*}{ Place of delivery } & Institution & $140(66.3)$ & $6(75)$ & $146(66.7)$ & \multirow[t]{2}{*}{0.7} \\
\hline & Home & $71(33.7)$ & $2(25)$ & $73(33.3)$ & \\
\hline \multirow[t]{2}{*}{ Birth weight } & Normal & $124(58.8)$ & $7(87.5)$ & $131(59.8)$ & \multirow[t]{2}{*}{0.14} \\
\hline & Low & $87(41.2)$ & $1(12.5)$ & $88(40.2)$ & \\
\hline \multirow[t]{2}{*}{ Birth order } & $>4$ & $122(57.8)$ & $1(12.5)$ & $123(56.2)$ & \multirow[t]{2}{*}{$0.02 *$} \\
\hline & $\leq 3$ & $89(42.2)$ & $7(87.5)$ & $96(43.8)$ & \\
\hline \multirow{2}{*}{$\begin{array}{l}\text { Inter-pregnancy } \\
\text { interval }\end{array}$} & $\geq 3$ years & $71(33.6)$ & $6(75)$ & $77(35.2)$ & \multirow[t]{2}{*}{$0.02 *$} \\
\hline & $<3$ & $140(66.4)$ & $2(25)$ & $142(4.8)$ & \\
\hline \multirow[t]{2}{*}{ Mothers Literacy } & Illiterate & $96(45.5)$ & $1(12.5)$ & $97(44.3)$ & \multirow[t]{2}{*}{0.07} \\
\hline & Literate & $115(54.5)$ & $7(87.5)$ & $122(55.7)$ & \\
\hline \multirow[t]{2}{*}{ SE Class } & IV-V & $98(46.4)$ & $1(12.5)$ & $99(45.2)$ & \multirow[t]{2}{*}{0.07} \\
\hline & II-III & $113(53.5)$ & $7(87.5)$ & $120(54.8)$ & \\
\hline \multirow[t]{2}{*}{ Gender of child } & Female & $117(55.5)$ & $2(75)$ & $123(56.2)$ & \multirow[t]{2}{*}{0.14} \\
\hline & Male & $94(44.5)$ & $6(25)$ & $96(43.8)$ & \\
\hline
\end{tabular}

$* p$ value $<0.05$

\section{Conclusion}

We conclude that the morbidity profile observed among the under-five children was similar to several other studies from India. History of exclusive breast feeding for 6 months, higher birth order ( $>4)$ and inter pregnancy interval for the index child ( $\geq 3$ years) were influencing the development of morbidity in the underfive children. However, immunization status of the child, place of delivery, birth weight, Mothers literacy status, Socio-economic class and gender of the child had no significant difference in distribution. Under-five is the most vulnerable group for mortality and this section of the population is the foundation of a healthy developed nation. Having healthy growth and development is not only a health related demand but also an issue of human rights. Thus appropriate costeffective strategies and intervention are needed to reduce the burden of morbidity in this critical age group

\section{Source of Funding: None}

Conflict of Interest: We declare we have no conflict of interest.

Acknowledgement: We are thankful to all the mothers of the children for their full co-operation during the study. 


\section{References}

1. UNICEF(2007). Progress for Children Report - A Statistical Review. December 2007.

2. Mishra CP(2010).Strategic issues in child health. Indian J Public Health, 54:75-80.

3. Joshi S. Child survival, Health \& Social work intervention (1996). Concept publishing company, New Delhi.

4. Gupta S, Jamwal DS, Kumar D, Gupta SK. Morbidity among under five children in a rural area of Jammu. JK Science. 2012 Apr 1;14(2):85.

5. World Health Organization (1991). Technical bases for the WHO recommendations on the management of pneumonia in children at first level health facilities. Geneva: WHO; 1991. (WHO/ARI/91.20.).

6. Age Structure and Marital Status. Census 2011 Available from :

http://censusindia.gov.in/Census_And_You/age_struct ure_and_maritxal_status.aspx (Accessed on 12.11.2017)

7. International classification of disease (ICD). World Health Organization; Available from http://www.who.int/classifications/icd/en/index.htm. (Accessed on 12.11.2017).

8. Khalid M, Kumari R, Mohan U, Manar KM, Singh VK. Morbidity profile of preschool children from below poverty line families of Lucknow district, North India. Int J Adv Res. 2014;2(11):627-34.

9. NFHS-4 Uttar Pradesh Factsheet. Available from: http://rchiips.org/NFHS/pdf/NFHS4/UP_FactSheet.pdf (Accessed on 20.4.2018)

10. Bharati P, Pal M, Bandyopadhyay M, Bhakta A, Chakraborty S, Bharati P. Prevalence and causes of low birth weight in India. Malays J Nutr. 2011 Dec 1;17(3):301-13

11. Broor S, Pandey RM, Ghosh M, Maitreyi RS, Lodha $\mathrm{R}$, Singhal T et al. Risk factors for severe acute lower respiratory tract infection in under-five children. Indian pediatrics. 2001 Dec 1;38(12):1361-9.

12. Mengistie B, Berhane Y, Worku A. Prevalence of diarrhea and associated risk factors among children under-five years of age in Eastern Ethiopia: A crosssectional study. Open Journal of Preventive Medicine. 2013 Oct 18;3(07):446.

13. Rutstein SO. Effects of preceding birth intervals on neonatal, infant and under-five years mortality and nutritional status in developing countries: evidence from the demographic and health surveys. International Journal of Gynecology \& Obstetrics. 2005 Apr 1;89(S1). 